\title{
Testing Classical Approach to Polymer Solutions on SAXS Data of $\lambda$-Carrageenan, $\kappa$-Carrageenan and Methylcellulose Systems
}

\author{
Jure Cerar, ${ }^{1}$ Andrej Jamnik ${ }^{1}$ and Matija Tomšič ${ }^{1, *}$ \\ ${ }^{1}$ University of Ljubljana, Faculty of Chemistry and Chemical Technology, Večna pot 113, SI-1000 Ljubljana, Slovenia \\ *Corresponding author: E-mail: Matija.Tomsic@fkkt.uni-lj.si
}

Received: 29-01-2015

Dedicated to Prof. Dr. Jo e Koller on the occasion of his $70^{\text {th }}$ birthday.

\begin{abstract}
In this paper we present the performance of the classical approach to polymer solutions in evaluation and interpretation of the experimental SAXS data obtained for aqueous solutions of two gelling polysaccharides $\kappa$-carrageenan and methylcellulose and a non-gelling polysaccharide $\lambda$-carrageenan. In a systematic structural SAXS study of various types of polymer solutions we pointed out and discussed the issues encountered and connected to the fact that the studied gels are obviously not "homogeneous gels" in terms of the structural details that the SAXS technique can resolve and the issues connected to the limited experimental resolution of the SAXS technique for such systems. In parallel the necessary modifications of the classical approach equations for the evaluation of the SAXS data are discussed. Furthermore, the detailed structural results of the studied aqueous polymeric systems in liquid state, during the onset of the gelation, and even in the gel state are presented.
\end{abstract}

Keywords: SAXS, Polymer Solutions, Sol-gel transition, Dynamic Correlation Length, Static Correlation Length, Debye-Bueche, Ornstein-Zernike.

\section{Introduction}

Methylcellulose (MC) and $\kappa$-carrageenan $(\mathrm{KC})$ are well known food additives (E407 and E461, respectively) that are commonly used as gelling, thickening and stabilizing agents. They are both known to form gelling aqueous polymer solutions, where $\mathrm{KC}$ forms hydrogel at lower temperatures and gradually "melts" into viscous solution with increasing temperature. Similarly, but opposite, the MC forms viscous solution at lower temperatures whereas the hydrogel at higher temperatures. Both polymers are known to show hysteresis in the temperature of sol-gel transition with heating and cooling the system. The transition temperatures of aqueous solutions of both polymers have already been thoroughly studied previously utilizing a variety of different techniques. ${ }^{1,2}$ Although $\mathrm{KC}$ and $\mathrm{MC}$ are very similar in structure, their gelling mechanisms differ significantly and have been extensively studied in the case of both polymers. ${ }^{3-7}$ It is namely generally accepted that the gelation of $\mathrm{KC}$ is a two-step process, where initially the transition from coils to double helices occurs with cooling and with further reduction of the temperature the double helices start to crosslink and form a three dimensional network. This results in the formation of an elastic gel. Since the KC molecules carry a charge due to the presence of the sulphate groups, the counter ions play a vital role in the gelation process. Their presence reduces repulsion between helices therefore a denser network and consequently a much stronger gel is formed. ${ }^{6}$ On the other hand, the mechanism of gelation of MC is explained by the three types of interactions: (i) the intramolecular hydrogen bonds between unmodified hydroxyl groups on the polymer chain, (ii) the hydrogen bonds between the hydroxyl groups on polymer chain and the solvent and (iii) the hydrophobic effect, due to the nonpolar nature of MC chains. Gel starts to form at higher temperatures when the hydration cage around MC chains starts to collapse and enables cross-linking between polymer chains and the formation of network due to the hydrophobic association. Also this gelation mechanism occurs in two recognizable steps; initially with the hydrophobic association and with further phase separation accompanied by the gelation. The phase separation on a micro scale is obvious, because in the gel state the samples are highly turbid and show also considerable syneresis. ${ }^{1,3}$ 
The primary goal of our study was to investigate the structure of $\mathrm{KC}$ and $\mathrm{MC}$ aqueous solutions and to monitor the structural changes during the thermally induced gelsol and sol-gel transitions utilizing the experimental small-angle X-ray scattering (SAXS) technique. For the evaluation and interpretation of the SAXS data we followed and adequately modified the so-called "classical approach" developed for the interpretation of similar SANS data on polymer solutions and gels. This approach was already extensively used and tested in the case of SANS on polymer solutions and simple gels ${ }^{8-15}$ and recently already also on some SAXS data. ${ }^{16-19}$ In the case of SAXS data one needs to account for the experimental broadening effects and correspondingly slightly modify the fitting scattering function. ${ }^{18,19}$ The latter approach was not yet extensively tested on the SAXS data of polymer solutions therefore one of our main interests was also a test of the performance of the theoretical scattering function used in the case of the studied gelling polymer systems. The main results of this model are presented in a form of the dynamic correlation length, corresponding to the correlation length of the "flexible" part of the polymer molecule between the entanglements, and the static correlation length, corresponding to the average size of the long-lived polymer entanglements characteristic for the gel-like structure.

\section{Experimental and Methods}

\section{1. Materials}

In this study the MC (Sigma Aldrich), KC (Fluka BioChemica) and LC (Sigma Aldrich) were used. Since the main goal of this study was to follow the structural properties of the solutions and their changes during the gelation process, the sample purity did not have important influence on the conclusion; therefore all polymers were used without further purification. The 4 wt. \% aqueous stock solutions of MC, KC and LC were prepared by weighting the polymer and water directly into the glass vials. The samples were homogenized by heating to approximately $70{ }^{\circ} \mathrm{C}$ during the vigorously stirring until the entire polymer was dissolved. Sample was then left to cool down over the night $\left(4^{\circ} \mathrm{C}\right)$. Samples for the SAXS measurements were prepared by weighting the stock solution directly and water into a glass vial. The $\mathrm{KC}$ stock solution was reheated to approximately $70{ }^{\circ} \mathrm{C}$ to melt down the gel before such weighting. We used deionized Milipore water.

\section{2. Small-Angle $X$-Ray Scattering Measurements}

Small-angle X-ray scattering spectra were obtained using a modified Kratky camera (Anton Paar, Graz, Austria) equipped with a Göbel mirror to obtain focused monochromatic beam. The camera was connected to X-ray generator (Philips, PW 3830/00) operating at $30 \mathrm{kV}$ and $50 \mathrm{~mA}$ with a sealed X-ray tube $\left(\mathrm{Cu} \mathrm{K}_{\alpha} ; \lambda=0.154 \mathrm{~nm}\right)$. All samples were measured in a standard quartz capillary with an outer diameter of $1 \mathrm{~mm}$ and wall thickness of 10 $\mu \mathrm{m}$. Scattering data were recorded using Mythen $1 \mathrm{~K}$ detector (Dectris, Baden, Switzerland). During the heating and cooling cycle the temperature was changed in a stepwise manner with a step of 2.5 or $5{ }^{\circ} \mathrm{C}$. At each step the samples were thermostated $\left( \pm 0.1^{\circ} \mathrm{C}\right)$ for 15 min using Peltier element and then measured for an hour. The temperature was changed from low to high temperatures and then back in order to study the hysteresis of sol-gel transition. Acquired scattering curves were normalized and the scattering curve of solvent (water) at given temperature was subtracted. Scattering data were further put on absolute scale using water as a secondary standard. ${ }^{20}$ Obtained data is presented as scattering function $I(q)$, where $q$ is the scattering vector $q=4 \pi / \lambda \cdot \sin (\vartheta / 2)$, with $\lambda$ being the wavelength of X-rays and $\vartheta$ the scattering angle. The experimental SAXS measurements were obtained in the following regime of the scattering vectors: $0.06 \mathrm{~nm}^{-1}<q<6$ $\mathrm{nm}^{-1}$. At this point we have to stress that the SAXS intensities obtained in this way were still experimentally smeared due to finite dimensions of the primary X-ray beam ${ }^{21}$ and therefore cannot be considered as the absolute intensities in a classical sense, therefore we mark their plots to be in arbitrary units [a.u.] and not in the units of $\left[\mathrm{cm}^{-1}\right]$.

\section{3. Evaluation of Small-Angle $X$-Ray Scattering Data}

It is known that in the polymer solutions the scattered light originates in the spontaneous thermodynamic fluctuations in local concentration around the equilibrium state. These fluctuations create inhomogeneities in the local electron density distribution that define the shape of the scattering curve. In such a case of homogenous polymer solutions the scattering curve can be described in the Ornstein-Zernike formalism by the function of the Lorentzian form: ${ }^{8,22}$

$$
I(q)=\frac{C}{1+q^{2} \xi^{2}}
$$

where $C$ is a constant and $\xi$ the dynamic correlation length corresponding to the length scale over which dynamical correlations decay in the network of the flexible polymer chains. The constant $C$ describes thermodynamic fluctuations of the polymer solution and is expressed as: ${ }^{8}$

$$
C=\Delta \rho^{2} \cdot k_{\mathrm{B}} \cdot T \cdot \frac{\phi^{2}}{K_{\mathrm{os}}}
$$

where $\Delta \rho$ is the difference in scattering contrast of the polymer, $k_{\mathrm{B}}$ the Boltzmann constant, $\phi$ the volume fraction of polymer, and $K_{\mathrm{OS}}$ the modulus of osmotic coefficient, that can be expressed as: ${ }^{8}$ 


$$
K_{\mathrm{OS}}=\phi \cdot \frac{\partial \Pi}{\partial \phi},
$$

where $\Pi$ is the osmotic pressure. While Equation (1) usually describes well the scattering curves of the free polymer chains in the homogeneous polymer solution, it fails in the case of scattering curves of the polymer gels. In the latter case the long-lived entanglements of the polymer molecules appear in the structure and introduce certain elasticity into the system. Strictly speaking also a single polymer chains in dilute solutions without intermolecular entanglements do exhibit some intrinsic intramolecular elasticity. Outer mechanical stress will namely lead to shear and the chain will adapt. Nevertheless, these effects are negligible compared to the system's elasticity induced by the intermolecular static entanglements. These entanglements have a major impact on the dynamic properties of the system therefore the local concentration fluctuations are no longer merely the consequence of random polymer motion (osmotic properties), but depend also on the system's elasticity. In such case the longitudinal osmotic module $M_{\mathrm{OS}}$ is introduced as: ${ }^{8}$

$$
M_{\mathrm{os}}=K_{\mathrm{OS}}+\frac{4}{3} G
$$

where $G$ represents the elastic module. The presence of the static entanglements in the structure causes an excess scattering contribution that is usually observed in the lower $q$ region of the scattering curve. Therefore Equation (1) cannot satisfactorily describe such scattering curve in this region and needs to be modified in such a case. This is achieved by an additional term, which describes the excess scattering in the low $q$ regime. In literature different additional terms were proposed. ${ }^{10,23}$ In this study we followed the well-known Debye-Beuche formalism leading to the following expression containing the Lorenzian and squared Lorentzian term: ${ }^{8,24}$

$$
I(q)=\frac{A}{1+q^{2} \xi^{2}}+\frac{B}{\left(1+q^{2} \Xi^{2}\right)^{2}}
$$

where $A$ and $B$ are constants and $\Xi$ an additional static correlation length corresponding to the dimensions to which the structure of static entanglements are correlated. Since in this case the dynamic properties of the system depend also on system's elasticity, the constant $A$ in Equation (5) differs from constant $C$ in Equation (1): ${ }^{8}$

$$
A=\Delta \rho^{2} \cdot k_{\mathrm{B}} \cdot T \cdot \frac{\phi^{2}}{M_{O S}} .
$$

The constant $B$ on the other hand corresponds to static fluctuations and can be expressed as: ${ }^{8}$

$$
B=8 \pi \cdot \Delta \rho^{2} \cdot \Xi^{3} \cdot\left\langle\partial \phi^{2}\right\rangle_{\mathrm{v}}
$$

where $\langle\partial \phi\rangle_{\mathrm{V}}$ is average local spatial fluctuation in volume fraction of the polymer.

\section{3. Experimental Smearing Effect}

Due to the experimental smearing effect which stem from the finite dimension of the primary X-ray beam, the measured scattering curves strongly depend on the geometry of the SAXS experiment. Although it possible to provide the desmeared scattering intensities with a sufficient accuracy using methods, such as LAKE algorithm or indirect Fourier transformation - IFT, ${ }^{23,24}$ we rather used different approach. The desmearing procedures are namely always based on some approximations or even some models, because the experimental scattering curves are only given in a limited $q$-range. On the other hand the theoretical scattering function is given in the whole $q$-range, therefore it is relatively easy to smear it numerically. The resulting smeared theoretical curve can then be directly fitted to the experimental data. ${ }^{25,26}$ The smearing effect arising from the finite length of the primary beam is described by the following equation: ${ }^{27}$

$$
\widetilde{I}(m)=\int_{-\infty}^{\infty} P(t) \cdot I\left(\sqrt{m^{2}+t^{2}}\right) d t
$$

where $\tilde{I}(m)$ is experimentally smeared scattering function, $I\left(\sqrt{m^{2}+t^{2}}\right)$ theoretical scattering function, $P(t)$ the length profile of primary beam and $t$ the direction perpendicular to scattering vector $q$ and represents the distance from the center of the primary beam. In this procedure we have not considered the smearing contribution due to the width profile of the primary beam, because this profile is very narrow in our setup and therefore has insignificant contribution to the smearing. The scattering profile of the primary beam used in our measurements is shown in Figure 1 and can be approximated with the following equation: ${ }^{19}$

$$
P(t)=\left\{\begin{array}{cc}
0 \leq t<t_{1} ; & \frac{1}{P_{0} t_{1}+P_{1} t_{2}} \cdot\left(\frac{\left(P_{1}-P_{0}\right)}{t_{1}} \cdot t+P_{0}\right) \\
t_{1} \leq t<t_{2} ; & \frac{1}{P_{0} t_{1}+P_{1} t_{2}} \cdot\left(\frac{P_{0} \cdot\left(t_{2}-t\right)}{t_{2}-t_{1}}\right) \\
t_{2} \leq t ; & 0
\end{array}\right\}
$$

where $P_{0}, P_{1}, t_{1}$, and $t_{2}$ are the geometrical parameters of the primary beam. It is imperative that both theoretical scattering function and profile of the primary beam are normalized in order to obtain smeared function on an absolute scale. If one combines Equation (1), Equation (8), and Equation (9), the integral can be solved analytically leading to the following expression: ${ }^{19}$ 


$$
\begin{aligned}
& I(q)=\frac{\mathrm{C}}{\left(t_{2}-t_{1}\right)\left(P_{0} \cdot t_{1}+P_{1} \cdot t_{2}\right)} \cdot \\
& \left\{\frac{1}{2 \xi^{2}} \cdot\left[\left(P_{1}-P_{0}\right) \cdot\left(\frac{t_{2}}{t_{1}}-1\right) \cdot \ln \left(\frac{1+\left(q^{2}+t_{1}^{2}\right) \cdot \xi^{2}}{1+q^{2} \xi^{2}}\right)+P_{1} \cdot \ln \left(\frac{1+\left(q^{2}+t_{1}^{2}\right) \cdot \xi^{2}}{1+\left(q^{2}+t_{2}^{2}\right) \cdot \xi^{2}}\right)\right]+\right. \\
& \left.+\frac{1}{\xi \sqrt{1+q^{2} \xi^{2}}} \cdot\left[\left(\left(P_{0}-P_{1}\right) \cdot t_{2}-P_{0} t_{1}\right) \cdot \tan ^{-1}\left(\frac{t_{1} \xi}{\xi \sqrt{1+q^{2} \xi^{2}}}\right)+P_{1} t_{2} \cdot \tan ^{-1}\left(\frac{t_{2} \xi}{\xi \sqrt{1+q^{2} \xi^{2}}}\right)\right]\right\}
\end{aligned}
$$

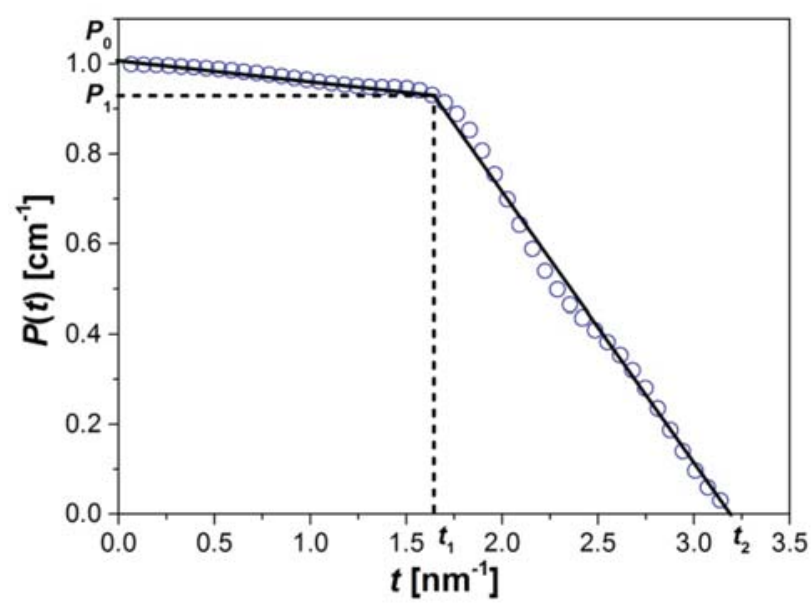

Figure 1: The approximation of the "length" profile of the X-ray primary beam with two lines.

Similarly, combining Equation (5), Equation (8), and Equation (9) one obtains the expression: ${ }^{19}$ sampling theorem of Fourier transformation $R_{\max }$ is given by

$$
R_{\max }=\frac{\pi}{q_{\min }} .
$$

Achievable resolution is thus half of the value which would follow from the Bragg law, $R_{\max }=2 \pi / q_{\min }$. Since the information on the long-ranged static correlating length $\Xi$ is predominantly expressed in the low- $q$ region of the scattering curve the experimental resolution defines the largest static correlating length $\Xi$ that could be determined based on the corresponding SAXS results. As in our experiment the $q_{\text {min }}$ was $0.06 \mathrm{~nm}^{-1}$ the resolution was around $52 \mathrm{~nm}$. However, in the case when the static correlation length $\Xi$ is above the resolution of the experiment, one is still able to resolve the value for the dynamic correlation length with satisfactorily precision by simply utilizing the Equation (1) or better Equation (10) and by taking into account only the outer part of the scattering curves obeying the following rule: ${ }^{9}$

$$
\begin{aligned}
& I(q)=\frac{1}{2\left(\mathrm{t}_{2}-\mathrm{t}_{1}\right)\left(\mathrm{P}_{0} \mathrm{t}_{1}+\mathrm{P}_{1} \mathrm{t}_{2}\right)} \cdot \\
& \left\{\frac{A \Xi^{2}}{\left(1+q^{2} \Xi^{2}\right)^{\frac{3}{2}}} \cdot\left[\left(\left(P_{0}-P_{1}\right) t_{2}-P_{0} t_{1}\right) \cdot \tan ^{-1}\left(\frac{t_{1} \Xi}{\sqrt{1+q^{2} \Xi^{2}}}\right)+P_{1} t_{2} \cdot \tan ^{-1}\left(\frac{t_{2} \Xi}{\sqrt{1+q^{2} \Xi^{2}}}\right)\right]+\right. \\
& +\frac{2 B}{\xi \sqrt{1+q^{2} \xi^{2}}} \cdot\left[\left(\left(P_{0}-P_{1}\right) t_{2}-P_{0} t_{1}\right) \cdot \tan ^{-1}\left(\frac{t_{1} \xi}{\sqrt{1+q^{2} \xi^{2}}}\right)+P_{1} t_{2} \cdot \tan ^{-1}\left(\frac{t_{2} \xi}{\sqrt{1+q^{2} \xi^{2}}}\right)\right]- \\
& \left.-\frac{B\left(P_{0}-P_{1}\right)\left(\mathrm{t}_{2}-\mathrm{t}_{1}\right)}{t_{1} \xi} \cdot \ln \left(1+\frac{t_{1}{ }^{2} \xi^{2}}{1+q^{2} \xi^{2}}\right)-\frac{P_{1} B}{\xi^{2}} \cdot \ln \left(\frac{1+\left(q^{2}+t_{2}^{2}\right) \cdot \xi^{2}}{1+\left(q^{2}+t_{1}^{2}\right) \cdot \xi^{2}}\right)\right\}
\end{aligned}
$$

In our study the primary beam with the following geometrical parameters was used: $P_{0}=1.01 \mathrm{~cm}^{-1}, P_{1}=$ $0.93 \mathrm{~cm}^{-1}, t_{1}=1.63 \mathrm{~nm}^{-1}$, and $t_{2}=3.20 \mathrm{~nm}^{-1}$.

\section{4. Considering Experimental Resolution}

At this point it is worth mentioning that the resolution of the SAXS experiment $R_{\max }$ depends on the lowest measurable value of the scattering vector $q_{\min }$. From the

$$
\xi \cdot q_{\min } \geq 1
$$

where $q_{\min }$ corresponds to the lowest value of the scattering vector that can still be considered in the fitting procedure. In Figure 2 we depict the results of such an approach on an example of the SAXS curve of $2 \mathrm{wt}$. \% KC aqueous solution, where the fits obtained according to Equations (10) and (11) are shown. For this system we were namely able to obtain information on $\xi$ and $\Xi$ according to Equa- 


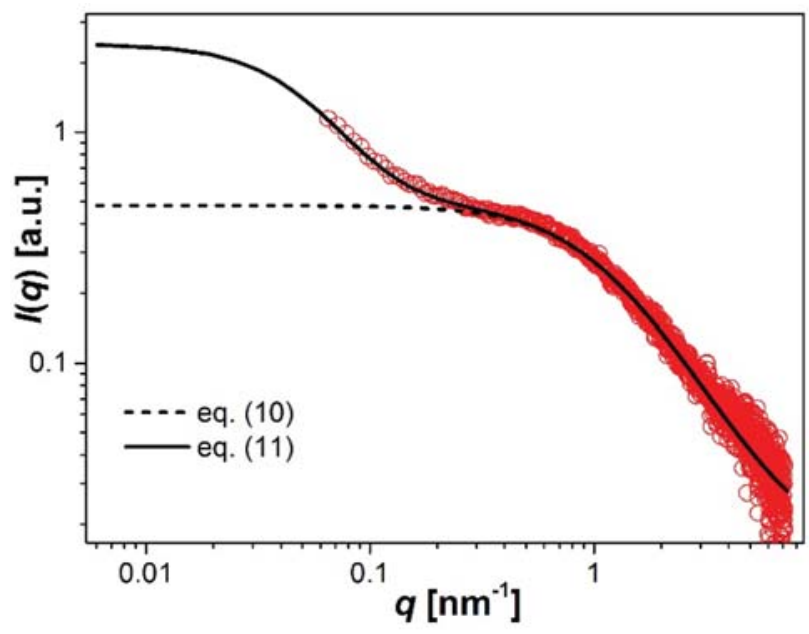

Figure 2: The resulting fits of Equation (10) (dashed line) and Equation (11) (solid line) to the experimental SAXS data of $2 \mathrm{wt}$. $\% \mathrm{KC}$ aqueous solution at $55^{\circ} \mathrm{C}$.

tion (11) and then we further used this example to show that the fit of Equation (10) to only the high $q$-region of the scattering curve, where the information about dynamic correlation length $\xi$ is predominantly expressed, provides a very good estimate of $\xi$. This example also clearly shows, why the fit based on Equation (10) cannot describe the scattering curve as well as Equation (11) in the central part of the scattering curve. The resulting values of $\xi$ and $\Xi$ obtained according to Equation (11) were $1.20 \mathrm{~nm}$ and $19.19 \mathrm{~nm}$, respectively, but the value of $\xi$ obtained according to Equation (10) was $1.24 \mathrm{~nm}$, which is within $~ 3.3 \%$ of the value $\xi$ obtained according to Equation (11).

\section{Results and Discussion}

In this systematic structural study of the gelation process we aimed to gain information on the quality of the performance of the classical approach for the evaluation of SAXS data of polymer solutions. This approach was namely originally developed and then also successfully applied mainly to the SANS data. ${ }^{7-15}$ Even though there are some similar studies available also on the SAXS data nowadays, we still miss thorough systematic reports on such analysis of experimental SAXS data. The lack of such studies could be reasoned by the necessity of some additional considerations that must be dealt with the SAXS data, i.e. the experimental broadening effect (smearing), and also by expectedly lower experimental resolution of the SAXS technique in respect to SANS. With our study we aimed to fill this gap and tried to carefully address and discuss the capabilities and limitations of such approach to SAXS data interpretation. To cover different structural situations with the SAXS data we have chosen to study two very different thermo-gelling polymers with very different gelling mechanisms: the $\mathrm{KC}$ that forms gel at low temperatures and the MC that gels at high temperatures. In order to parallel these results with a non-gelling polymer system we have also studied the aqueous solutions of $\lambda$-carrageenan (LC). The LC is chemically rather similar to the $\mathrm{KC}$, but in pure aqueous solutions does not form gel.

In Figure 3 the temperature dependence of the scattering of $\mathrm{LC}, \mathrm{KC}$, and $\mathrm{MC}$ aqueous solutions with concentrations of 2 and $1 \mathrm{wt}$ \% are shown. Comparing SAXS re-
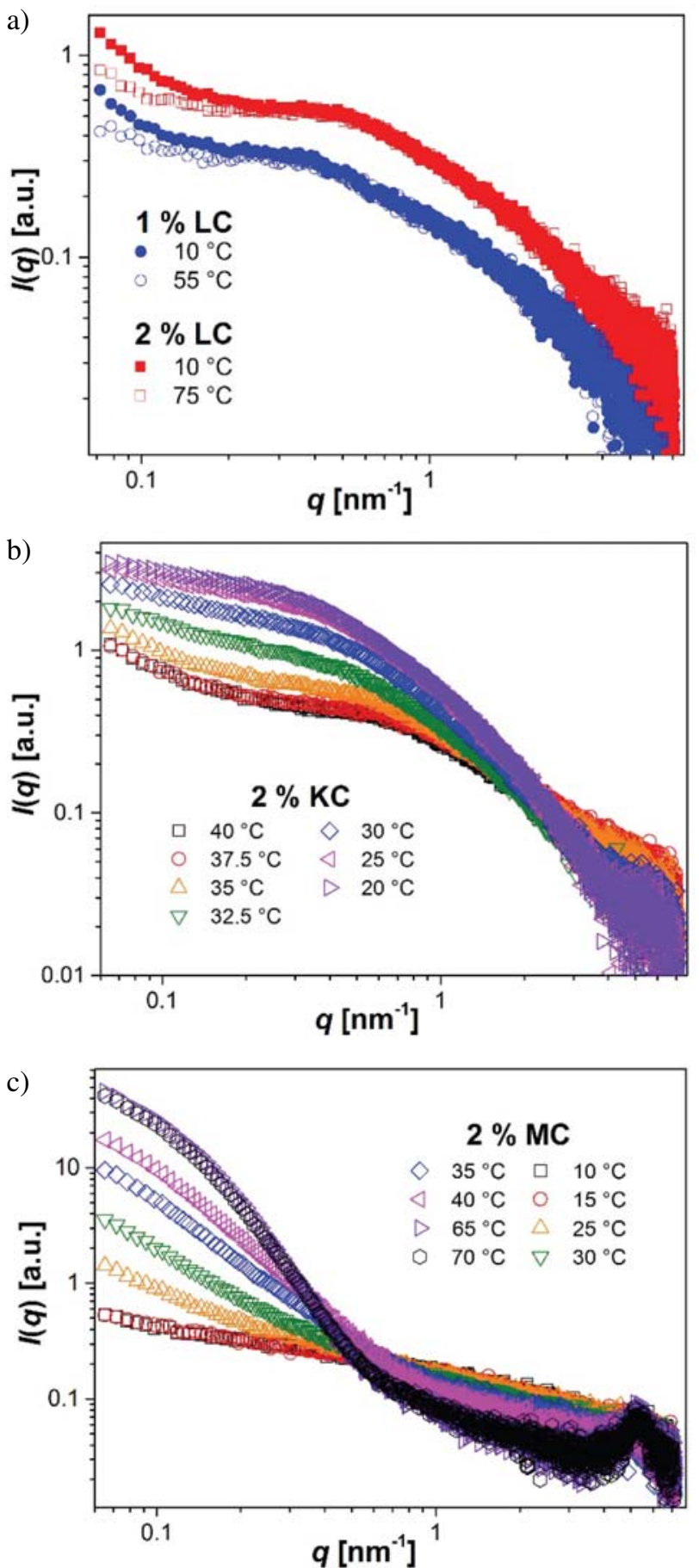

Figure 3: The experimental SAXS curves of 2 wt. \% (a) LC, (b) $\mathrm{KC}$, and (c) MC at different temperatures on a log-log scale. 
sults for LC, MC and KC one can clearly see that the temperature dependence of the SAXS spectra is rather strong for $\mathrm{KC}$ and $\mathrm{MC}$, but is relatively weak for the LC solutions. In the latter case the only change that is observed with the temperature increase is a slight decrease of the scattering in the low- $q$ regime, whereas the scattering curves practically coincide at larger values of $q$. We interpret this drop in the forward scattering intensity as the consequence of the decreasing intramolecular polymer entanglements with increasing thermal energy of the polymer molecules. These LC solutions are namely known to be non-gelling and stay viscous throughout the studied temperature regime - these effects are therefore considered to be mainly of intramolecular origin. It is also worth mentioning already at this point that in the case of SAXS data of viscous polymer solutions it has already been observed on a couple of occasions that the fits based on Equation (1) or better Equation (10) were not satisfactory. It turned out that the fits based on Equation (5) or better Equation (11) had to be used to satisfactorily describe such SAXS data even though these systems were clearly not in the gel state. ${ }^{19}$ Obviously there are some long-lived (presumably intramolecular) entanglements present already in the liquid state of such polymer systems and the SAXS technique seems to be more sensitive to these structural details in respect to the SANS method. Since the scattering contrast is conceptually different for both methods, it is therefore natural that they "see" the structure of the samples somewhat differently. As presented into details somewhat latter in the text, similar situation was also observed in the liquid state of $\mathrm{KC}$ and $\mathrm{MC}$ aqueous systems, i.e., the appearance of the long-lived polymer entanglements that contribute to the overall scattering of the systems.

It is well-known that the gelation of the $\mathrm{KC}$ occurs gradually during the cooling of the sample over a rather wide temperature range. ${ }^{1}$ The scattering curves of the $\mathrm{KC}$ solutions show practically no change with decreasing temperature prior to the onset of the gelation, but with further cooling the scattering intensity starts to increase. Once the sol-gel transition finishes further decrease of the temperature practically does not affect the scattering curves. In the direction of heating, i.e. for the gel-sol transition, just the opposite trend can be observed for KC samples, but with a strong thermal hysteresis. Similarly, but opposite, the MC system transforms to gel at high temperatures and reverses to viscous solution once the temperature is dropped - again with the considerable thermal hysteresis. ${ }^{1,4}$ The gelation of the MC sample causes a steep increase of the scattering intensity at very low $q$-values. However, surprisingly during the sol-gel transition of MC also a sharp peak begins to rise in the scattering curve at $q$ value around $5.5 \mathrm{~nm}^{-1}$. Based on this value we can conclude that this scattering feature obviously corresponds to some fairly small structural segment of about 1.1 $\mathrm{nm}$ in size that is obviously characteristic for the MC gelation. At this point we cannot say anything more definite regarding this structural feature. Nevertheless, as the MC gels are known to show considerable syneresis, i.e. they expel considerable amounts of water with time, this could be a sign that very small water "pockets" form within the structure of the MC gel already during the gelation process. There are namely some reports available that microphase separation occurs during the gelation of the $\mathrm{MC}^{3}$

For detailed interpretation of the experimental SAXS data we applied Equation (10) and (11). Such approach provided us with the dynamic correlation length $\xi$ corresponding to the distance to which the flexible parts of the polymer chains are correlated and in case of Equation (11) also with the static correlation length $\Xi$ corresponding to the dimensions to which the regions of long-lived static entanglements are correlated. Such static entanglements introduce some elasticity into the structure of the polymer systems that eventually causes the formation of the gel-like structure in such systems. The performance of this approach for the studied polymer systems can be seen via the quality of the fits to the experimental SAXS data that are shown in Figure 4. For the sake of clarity only the fits of Equation (11) at temperature extremes (lowest and highest studied temperature) are depicted for all three studied polymer systems. As already mentioned earlier in the text, the best fits to the SAXS curves of the LC system were obtained utilizing Equation (11), which is an interesting fact considering these systems are known to be non-gelling. The fits were satisfactory in the whole studied temperature regime, but the problem was that the resulting $\Xi$ values were highly above the resolution of our SAXS experiment and therefore could not be determined with acceptable precision - the SAXS technique could not provide the data to $q$-values that would be low enough to contain sufficient information on such high values of $\Xi$. Therefore we rather used Equation (10) and only the outer part of the scattering curves to gain the values of dynamic correlation length. The resulting $\xi$ was $1.29 \mathrm{~nm}$ for $2 \mathrm{wt}$. $\% \mathrm{LC}$ solutions and $1.54 \mathrm{~nm}$ for $1 \mathrm{wt}$ \% LC solutions (the latter data not shown) and remained practically constant throughout the studied temperature regime within $\sim 9 \%$. This was expected, since the scattering curves practically did not change in the higher $q$-region. The decrease of the $\xi$ value with the increase of the polymer concentration has already been observed for other polymer systems with prevailing repulsive interparticle interactions ${ }^{19}$ and can be reasoned with the fact that increasing the polymer concentration the polymer volume fraction increases leading to smaller space per polymer molecule and correspondingly stronger interparticle interactions and dynamics in the system. Namely, in the case of viscous LC solutions the interparticle interactions are predominantly repulsive therefore correspondingly smaller dynamic correlation length $\xi$ values are obtained with an increase of the polymer concentration. In such a case one would expect also the reduction in the static correlation length $\Xi$ parameter, which would in such case correspond to the intramolecu- 

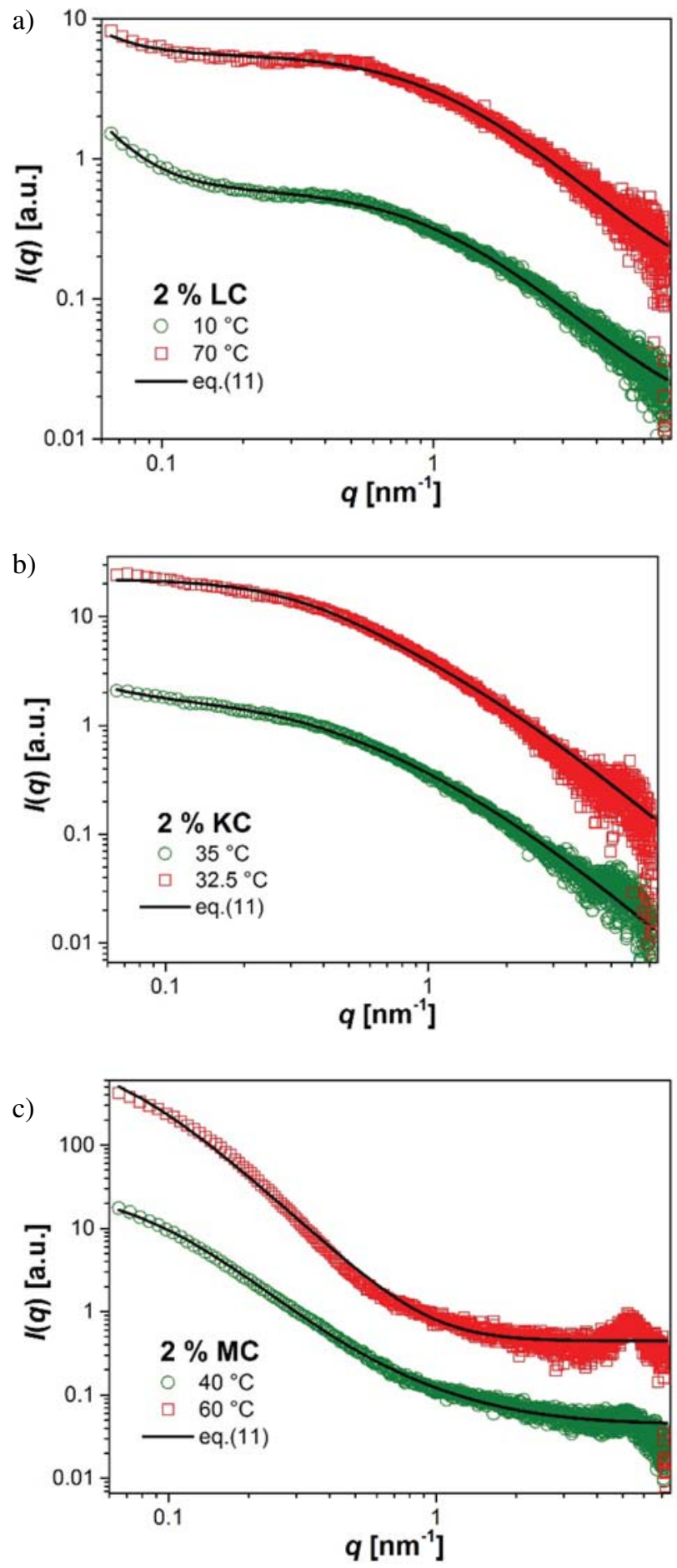

Figure 4: The fits of Equations (10) to experimental scattering curves of 2 wt. \% (a) LC, (b) KC, and (c) MC at various temperatures. Curves have been shifted by a constant value for the sake of clarity.

lar entanglements, but this parameter unfortunately could not be determined unambiguously due to the insufficient experimental resolution.

In Figure $4 \mathrm{~b}$ one can see that for $\mathrm{KC}$ system Equation (11) gives a good fit only at high temperatures where the system is in a form of viscous solution, but it fails at low temperatures where this system is in a form of a gel. Just the opposite we observe for MC system where the fits of Equation (11) were good at low temperatures and failed at higher temperatures where the gelation occurred. As it turned out utilizing the Equation (11) we could only monitor the structural changes of the viscous solutions, the onset of the sol-gel transition and the final stage of the gel-sol transition, whereas we were not able to follow the structural changes in the gels of either $\mathrm{KC}$ as also $\mathrm{MC}$ polymer systems. The corresponding results for $\Xi$ and $\xi$ in the temperature regime where Equation (11) does a good job are depicted in Figure 5a for $\mathrm{KC}$ and Figure $5 \mathrm{~b}$ for MC system.

As can be seen in Figure 5a, we were able to follow a rapid decrease of the $\Xi$ values (from cca. $30 \mathrm{~nm}$ to cca. $15 \mathrm{~nm}$ ) during the final stage of the melting of the $\mathrm{KC}$ gel structure observed around $45{ }^{\circ} \mathrm{C}$ with the temperature increase. Similarly in the next step the onset of the gelation could be followed through a sudden increase of $\Xi$ values (from cca. $15 \mathrm{~nm}$ to $25 \mathrm{~nm}$ ) around $35^{\circ} \mathrm{C}$ with the temperature decrease. Very similar trends were observed also for the MC system in Figure 5b, where we could follow the increase of the $\Xi$ values (from cca. $5 \mathrm{~nm}$ to cca. $14 \mathrm{~nm}$ ) around $40{ }^{\circ} \mathrm{C}$ during the onset of the sol-gel transition with the temperature increase, as also the decrease of the $\Xi$ values (from cca. $13 \mathrm{~nm}$ to cca. $5 \mathrm{~nm}$ ) around $20^{\circ} \mathrm{C} \mathrm{du}-$ ring the final stage of the gel-sol transition with the temperature decrease. Such changes in the values of $\Xi$ are logical, because $\Xi$ represents the static correlation length representing the long-lived polymer entanglements that are expected to progress during the formation of the gel-like structure and regress during its "melting". In Figure 5 one can also see that in parallel to changes in the parameter $\Xi$ also the changes in parameter $\xi$ occur. The value of the dynamic correlation length is namely considerably lower in the state of the viscous polymer solution than during the state of transition sol-gel or gel-sol, therefore the changes of $\xi$ seem to follow the changes of $\Xi$. During the process of the gelation the static polymer entanglements progress in the structure and consequently the whole polymer molecule becomes more and more rigid. Correspondingly also the dynamic parts of the polymer molecule between the static entanglements becomes correlated on larger distances, which reflects in higher values of $\xi$, as is actually observed in our results.

In both gelling polymer systems problems fitting Equation (11) were encountered at the conditions where the systems were in a form of solid gels. The fact that the resolution of the SAXS experiment is relatively low certainly causes a strong ambiguity in fitting the scattering curves in the regime of low- $q$ values. On the other hand we have to stress that the classical approach to the polymer solutions assumes the homogeneous polymer solutions and the gels that form due to the appearance of the long-lived polymer entanglements in the structure. Such 

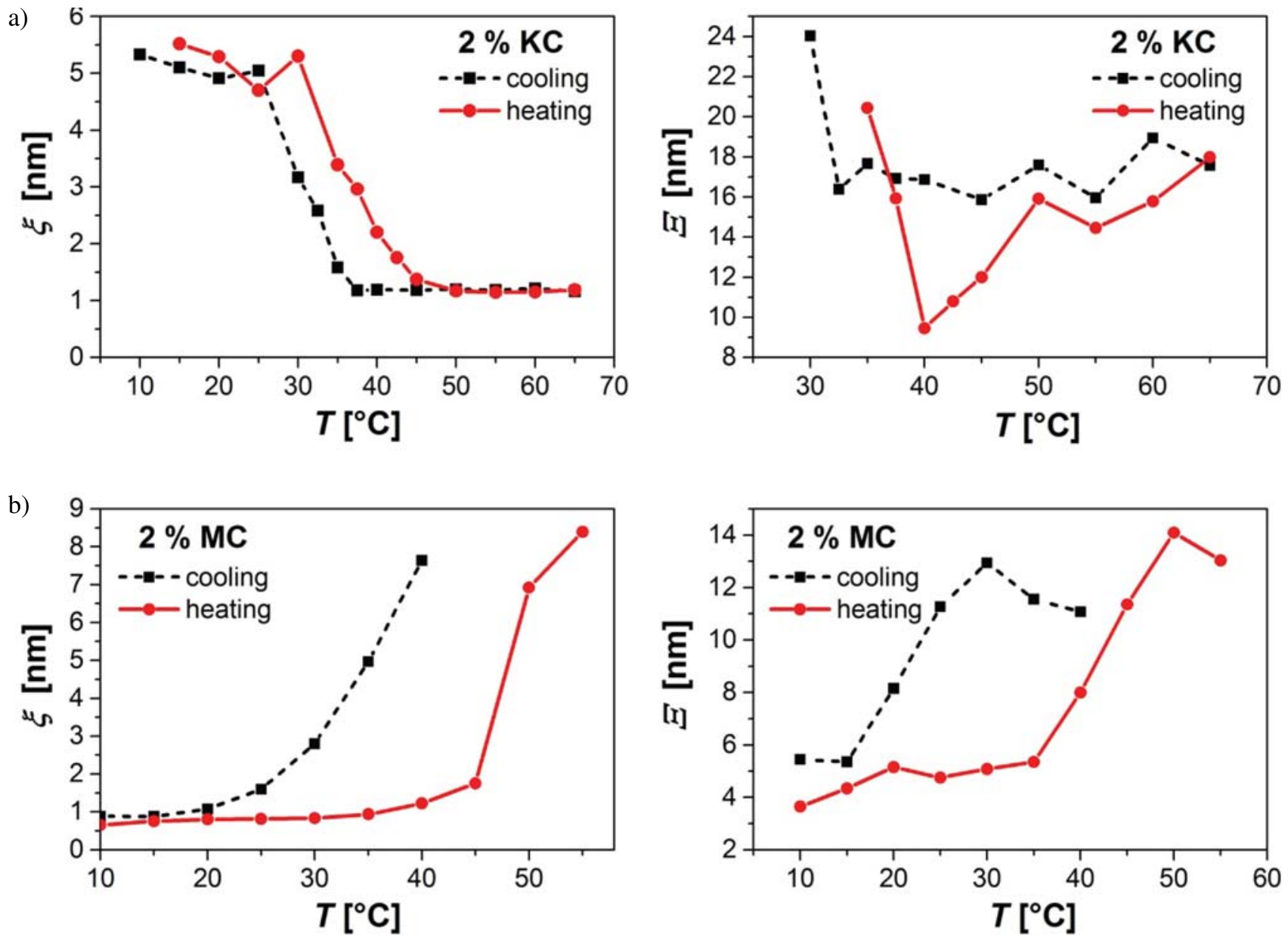

Figure 5. Thermally induced change of the dynamic and static correlation lengths $\xi$ and $\Xi$ in 2 wt. \% (a) KC and (b) MC system. The results are shown only for the temperature regime where Equation (11) performs well.

entanglements raise the elastic nature of the polymer system and are described solely by the static correlationlength parameter. The latter means that they are as such considered as somewhat denser (homogeneous) polymer regions within the system. Therefore one could argue that there is no consideration of possible further nano-structuration of these regions taken into account in the classical approach. If these denser regions with the static entanglements would not be homogeneous, but rather some nanostructured details would be present in its structure, one would certainly expect them to reflect in an additional scattering contribution in the scattering curve that would cause Equation (11) to become inappropriate for such a case. As Equation (11) severely fails to reproduce the scattering curves of the gels in the low- $q$ region in Figure 4, this certainly strongly indicates on an additional scattering contribution present in these system. This explanation is even more plausible due to the fact that the gelation mechanism of $\mathrm{KC}$ is known to comprise the formation of the double helices of $\mathrm{KC}$ molecules and their subsequent aggregation into complex gel network. ${ }^{6}$ Such gelation mec- hanism most certainly introduces some nanostructure into these gels at least on the level of double helices and their aggregates. Similarly, also in the case of MC systems the discrepancy from the structure of a "homogeneous gel" is obvious already observed from the peak arising with the gelation in the moderate $q$ regime. At this point we have to stress that very similar features of bad fits of Equation (11) were recently observed also in the case of SAXS data of nonionic polysaccharide levan samples - they were attributed to the contribution of the eventual nanostructure on the surface or interior of the very large polymer particles that were observed in these systems microscopically. ${ }^{19}$

Even though Equation (11) fails to interpret the scattering curves of $\mathrm{KC}$ and $\mathrm{MC}$ gels, we can still evaluate the outer part of these scattering curves utilizing the Equation (10) and obtain the values of dynamic correlation length $\xi$ even for the gels. The results of such an approach to the evaluation of temperature dependent SAXS curves of KC and $\mathrm{MC}$ at various concentrations are depicted in Figure 6. Nevertheless, this approach is somewhat limited in the case of the MC gels due to the scattering maximum that 
develops around $q$ value of $5.5 \mathrm{~nm}^{-1}$ (see Figure 3c) - we are therefore not able to get trustworthy $\xi$ values for MC gel.

It is interesting to see that the curves in Figure 6a seem to show a plateau at low temperatures indicating that $\xi$ settles at more or less constant value that is dependent on the polymer concentration. This is in accordance with the fact that the scattering curves of KC system practically coincide once the gel is fully formed. One can further observe that the value of $\xi$ increases with increasing $\mathrm{KC}$ concentration at low temperatures. This occurs due to the increasing stiffness of the KC gels with increasing concentration that in turn reflects also in the lower flexibility of the polymer molecule parts between the static entanglements leading to higher dynamic correlation lengths. However, this trend is reversed at higher temperatures in the regime of the viscous $\mathrm{KC}$ solutions, where the value of $\xi$ decreases with increasing KC concentration - at this stage we have to point out that a very similar trend was observed already in the case of the non-gelling LC system and
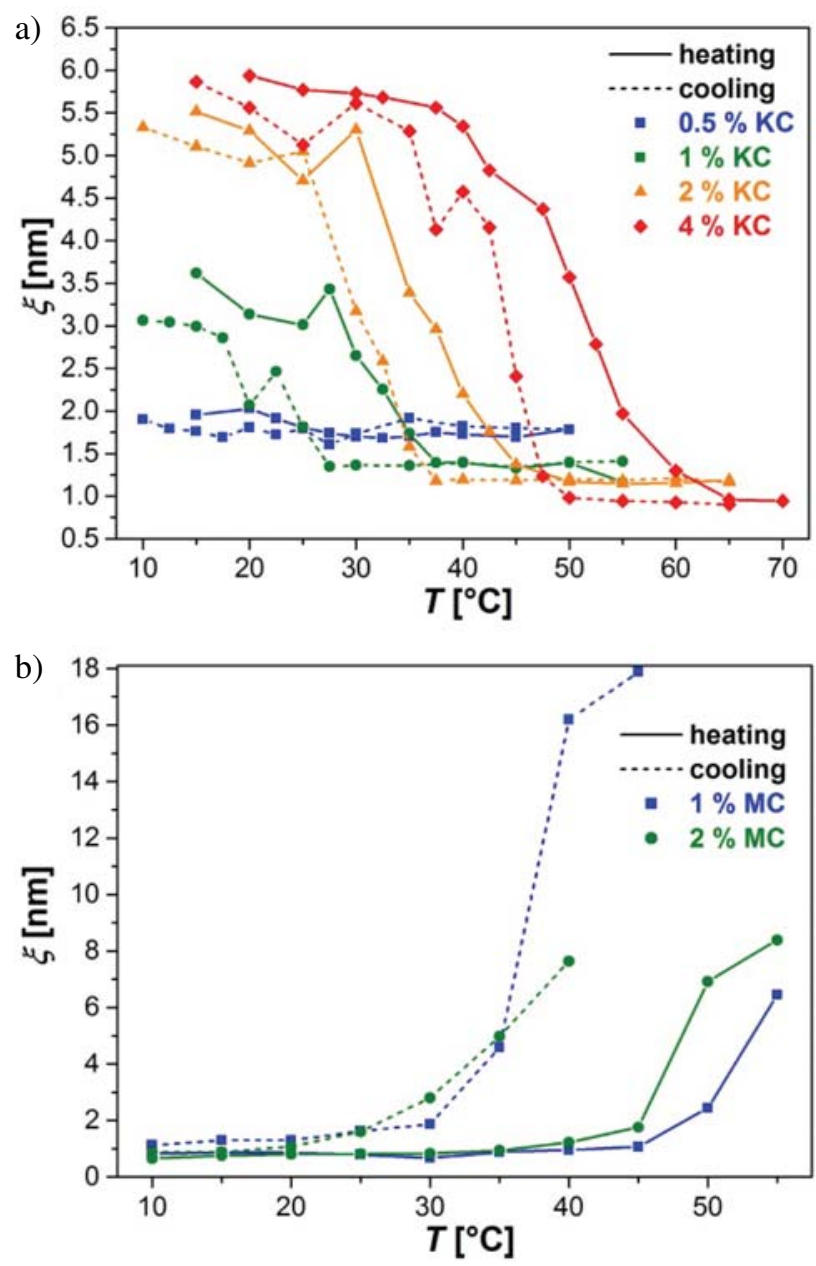

Figure 6: The temperature dependence of the dynamic correlation length $\xi$ for polymer solutions of (a) KC and (b) MC at different concentrations. as can be seen from the results for $\xi$ gathered in the Table 1 , it obviously holds even for the nonionic MC system. Such a trend can namely be explained as the effect of predominating repulsive interparticle interactions that are characteristic for stable viscous solutions - the reduction of $\xi$ is the consequence of the increase in the polymer dynamics due to increase of the strength of the repulsive interparticle interactions.

Table 1. The average values of the dynamic correlation length $\bar{\xi}$ for 1 and 2 wt. \% viscous solutions of $\mathrm{LC}, \mathrm{KC}$, and MC.

\begin{tabular}{llll}
\hline & $\overline{\boldsymbol{\xi}}\left[\mathbf{n m}^{\mathbf{- 1}}\right]$ & & \\
& $\mathbf{L C}$ & KC & MC \\
\hline $1 \%$ & 1.54 & 1.38 & 0.97 \\
$2 \%$ & 1.29 & 1.20 & 0.92 \\
$\Delta \xi$ & 0.25 & 0.18 & 0.05 \\
\hline
\end{tabular}

Another very interesting observation can be made based on the results gathered in Table 1 and further reveal high level of details that such classical approach can provide from SAXS data. The resulting values of $\xi$ seem to be somewhat larger for $\mathrm{LC}$ in respect to the ones for $\mathrm{KC}$, but both seem to be noticeably higher than those of MC. $\mathrm{LC}$ and $\mathrm{KC}$ are chemically very similar polysaccharide molecules, the only significant difference being that LC contains three, but $\mathrm{KC}$ only one $\mathrm{SO}_{4}^{-}$group per monomer polymer unit. The charge density on the polymer backbone is therefore much higher in the case of LC, which is also the main reason that pure LC aqueous solutions are non-gelling. Due to the stronger electrostatic repulsion between the monomer units the LC molecules are more elongated and rigid in respect to $\mathrm{KC}$ molecules; therefore their dynamic correlation length $\xi$ is expectedly higher. On the other hand the MC is nonionic polysaccharide and consequently does not exhibit long-range electrostatic repulsions between the monomer units, therefore the MC molecules are more flexible and their $\xi$ values expectedly noticeably smaller as in the case of KC and LC. Due to the same reason also the decrease of the dynamic correlation length $\Delta \bar{\xi}$ with the increase in the polymer concentration in the viscous solution state is considerably smaller for the nonionic $\mathrm{MC}$ in respect to the ionic $\mathrm{KC}$ and $\mathrm{LC}$, as also seen in Table 1.

\section{Conclusions}

In this paper we present the results of the systematic structural SAXS study of the aqueous polysaccharide solutions of LC, KC and MC. For the experimental SAXS data evaluation and their interpretation the equations of the classical approach to polymer solutions, which had to be slightly modified, were used. This approach turned out to be quite powerful also for the SAXS data interpretation 
of polymer solutions and transitions to gels, but it also showed some shortcomings in the case when the static correlation-lengths rise above the experimental resolution and static-entanglement regions exhibit some characteristic internal nanostructure. In this manner the presented results reminded us that the experimental SAXS resolution is relatively limited for such samples; therefore the static correlation lengths could not be determined in all of the studied systems. Furthermore, both KC and MC gels obviously contain some details in their structure that bring up an additional scattering contribution in the low- $q$ regime of the SAXS spectra and yield the equation of the classical approach to polymer solutions to fail to describe them. In such a case one could try to use the modeling approach. $^{28-30}$

The presented results clearly show that in the case of both $\mathrm{KC}$ and $\mathrm{MC}$ systems the dynamic correlation length $\xi$ increases as the gel is formed. This is due to the fact that the dynamic parts of the polymer chains shorten between the progressing static entanglements and consequently become more rigid - they are correlated to longer distances $\xi$. This is also in agreement with the fact that $\mathrm{KC}$ molecules form double helices upon gelation, which are more rigid structures as single chains. Similarly in the process of gelation also the static correlation length increases and the opposite occurs during the "melting" of the gel. We could also see the reduction of the dynamic correlation length with increasing polymer concentration in liquid polymer solution, which occurred due to the increase of the strength of repulsive interparticle interactions and the corresponding increase in the polymer dynamics with increasing concentration. Interestingly, the measured SAXS data for the studied polymer solutions showed the presence of the long-lived polymer entanglements in all solutions already in the liquid state, which is a feature that has already been observed with the SAXS data in a couple of occasions by now.

\section{Acknowledgment}

We are grateful to prof. Otto Glatter for his generous contribution to the instrumentation of our laboratory for the light scattering methods. We are also tankful to Slovenian Research Agency for their financial support (program P1-0201).

\section{References}

1. M. Tomšič, F. Prossnigg, O. Glatter, J. Colloid Interf. Sci. 2008, 322, 41-50.

http://dx.doi.org/10.1016/j.jcis.2008.03.013

2. M. Tomšič, S. Guillot, L. Sagalowicz, M. E. Leser, O. Glatter, Langmuir 2009, 25, 9525-9534.

http://dx.doi.org/10.1021/la900766c
3. K. Kobayashi, C.-i. Huang, T. P. Lodge, Macromolecules 1999, 32, 7070-7077.

http://dx.doi.org/10.1021/ma990242n

4. M. Takahashi, M. Shimazaki, J. Yamamoto, J. Polym. Sci. Part B: Polym. Phys. 2001, 39, 91-100. http://dx.doi.org/10.1002/1099-0488(20010101)39:1<91:: AID-POLB80>3.0.CO;2-C

5. Y. Yuguchi, T. T. T. Thuy, H. Urakawa, K. Kajiwara, Food Hydrocolloids 2002, 16, 515-522.

http://dx.doi.org/10.1016/S0268-005X(01)00131-X

6. E. V. Shtykova, E. V. Shtykova, V. V. Volkov, P. V. Konarev, A. T. Dembo, E. E. Makhaeva, I. A. Ronova, A. R. Khokhlov, H. Reynaers, D. I. Svergun, J. Appl. Crystallogr. 2003, 36, 669-673. http://dx.doi.org/10.1107/S0021889803006198

7. T. Chatterjee, A. I. Nakatani, R. Adden, M. Brackhagen, D. Redwine, H. W. Shen, Y. F. Li, T. Wilson, R. L. Sammler, Biomacromolecules 2012, 13, 3355-3369.

http://dx.doi.org/10.1021/bm301123a

8. E. Geissler, f. Horkay, A.-M. Hecht, C. Rochas, P. Lindner, C. Bourgaux, G. Courrazze, Polymer 1997, 38, 15-20. http://dx.doi.org/10.1016/S0032-3861(96)00490-9

9. F. Horkay, A. M. Hecht, E. Geissler, Macromolecules 1998, 31, 8851-8856. http://dx.doi.org/10.1021/ma971606j

10. G. Evmenenko, E. Theunissen, K. Mortensen, H. Reynaers, Polymer 2001, 42, 2907-2913.

http://dx.doi.org/10.1016/S0032-3861(00)00674-1

11. B. Hammouda, D. L. Ho, S. Kline, Macromolecules 2004, 37, 6932-6937. http://dx.doi.org/10.1021/ma049623d

12. M. Shibayama, K. Isono, S. Okabe, T. Karino, M. Nagao, Macromolecules 2004, 37, 2909-2918. http://dx.doi.org/10.1021/ma0359685

13. I. Hoffmann, P. Heunemann, S. Prevost, R. Schweins, N. J. Wagner, M. Gradzielski, Langmuir 2011, 27, 4386-4396. http://dx.doi.org/10.1021/la104588b

14. J. Sharma, V. K. Aswal, P. S. Goyal, H. B. Bohidar, Macromolecules 2001, 34, 5215-5220. http://dx.doi.org/10.1021/ma0022194

15. E. M. Saffer, M. A. Lackey, D. M. Griffin, S. Kishore, G. N. Tew, S. R. Bhatia, Soft Matter 2014, 10, 1905-1916. http://dx.doi.org/10.1039/c3sm52395k

16. E. Shtykova, A. Dembo, E. Makhaeva, A. Khokhlov, G. Evmenenko, H. Reynaers, Langmuir 2000, 16, 5284-5288. http://dx.doi.org/10.1021/la991357n

17. A. M. Hecht, F. Horkay, P. Schleger, E. Geissler, Macromolecules 2002, 35, 8552-8555. http://dx.doi.org/10.1021/ma020507p

18. I. Dogša, Kriechbaum M., Stopar D., Laggner P., Biophys. J. 2005, 89, 2711-2720. http://dx.doi.org/10.1529/biophysj.105.061648

19. E. Benigar, I. Dogsa, D. Stopar, A. Jamnik, I. K. Cigic, M. Tomšič, Langmuir 2014, 30, 4172-4182. http://dx.doi.org/10.1021/la500830j

20. D. Orthaber, A. Bergmann, O. Glatter, J. Appl. Crystallogr. 2000, 33, 218-225.

http://dx.doi.org/10.1107/S0021889899015216 
21. O. Glatter Data treatment, Academic Press: United Kingdom, 1983.

22. P. G. de Gennes Scaling Concepts in Polymer Physics, Cornell University Press: Itacha, New York, 1979.

23. B. Hammouda, D. Ho, S. Kline, Macromolecules 2002, 35 , 8578-8585. http://dx.doi.org/10.1021/ma011657n

24. P. Debye, A. M. Bueche, J. Chem. Phys. 1948, 16, 573. http://dx.doi.org/10.1063/1.1746948

25. O. Glatter, Journal of Applied Crystallography 1977, 10, 415-421. http://dx.doi.org/10.1107/S0021889877013879

26. J. A. Lake, Acta Crystallographica 1967, 23, 191-194. http://dx.doi.org/10.1107/S0365110X67002440
27. O. Glatter, in: O. Glatter, O. Kratky (Eds.): Small angle x-ray scattering, Academic Press Inc. London Ltd., London, 1983, pp. 119-165.

28. I. Dogša, J. Štrancar, P. Laggner, D. Stopar, Polymer 2008 , 49, 1398-1406. http://dx.doi.org/10.1016/j.polymer.2008.01.043

29. J. Orehek, I. Dogsa, M. Tomšič, A. Jamnik, D. Kocar, D. Stopar, Int. Biodeter. Biodegr. 2013, 77, 10-17. http://dx.doi.org/10.1016/j.ibiod.2012.10.007

30. I. Dogsa, M. Tomšič, J. Orehek, E. Benigar, A. Jamnik, D. Stopar, Carbohyd. Polym. 2014, 111, 492-504. http://dx.doi.org/10.1016/j.carbpol.2014.04.020

\section{Povzetek}

V tem prispevku predstavljamo uporabo in zmogljivosti klasičnega pristopa k obravnavi polimernih raztopin in sicer na primeru ovrednotenja in interpretacije eksperimentalnih podatkov metode SAXS. Ti podatki so bili pridobljeni tekom sistematične strukturne raziskave različnih tipov polimernih vodnih raztopin: dveh gelirajočih polisaharidov $\kappa$-karagenana in metil celuloze ter negelirajočega polisaharida $\lambda$-karagenana. $V$ študiji smo izpostavili in obravnavali težave $v$ povezavi z dejstvom, da proučevani geli očitno niso »homogeni geli« v smislu strukturnih podrobnostih, ki jih lahko iz sipalnih krivulj razloči tehnika SAXS, in težave povezane $\mathrm{z}$ omejeno eksperimentalno ločljivostjo metode SAXS za takšne polimerne sisteme. Vzporedno smo predstavili tudi potrebne transformacije enačb klasičnega pristopa k obravnavi polimernih raztopin, ki so potrebne za ustrezno vrednotenje podatkov SAXS. Poleg tega so v tem delu predstavljeni tudi podrobni konkretni rezultati o strukturi vodnega sistema posameznega raziskovanega polisaharida v tekoči raztopini, med nastopom geliranja in tudi v stanju gela. 